Influence of Platelets Rich Plasma on Repair of Superficial Digital Flexor Tendon Rupture in Donkeys (An Experimental Study)

\author{
Mohamed T. Samy ${ }^{1}$, Mohamed S.A. Omar ${ }^{1}$, Fathy D. Elseddawy ${ }^{1}$, Eslam F.M. Eisa ${ }^{1 *}$ and \\ Mohamed M.M. Metwally ${ }^{2}$ \\ ${ }^{1}$ Surgery, Anesthesiology and Radiology Department, Faculty of Veterinary Medicine, Zagazig \\ University, 44511, Egypt \\ ${ }^{2}$ Pathology Department, Faculty of Veterinary Medicine, Zagazig University, 44511, Egypt \\ Article History: Received: 20/6/2017 Received in revised form: 27/8/2017 Accepted: 10/9/2017
}

\begin{abstract}
This study was planned to prospectively evaluate the influence of platelets rich plasma (PRP) on the restoration of superficial digital flexor tendon (SDFT) in donkeys. Eighteen apparently clinically healthy male donkeys of 3-6 years old, weighing 150-200 kg, were used. The animals were classified into two equal groups; control group and PRP group. One cm transection of the full thickness of middle portion of the SDFT was made in all animals. First, all animals were subjected to sedation via xylazine $\mathrm{HCl}$ injection in a dose of $1 \mathrm{mg} / \mathrm{kg}$ body weight then the animals were deeply narcotized with chloral hydrate $10 \%$ in a dose of $5 \mathrm{gm} / 50 \mathrm{~kg}$ body weight. A linear skin incision in the palmar aspect of the right fore limb at the mid cannon region was performed in all operated animals. The animals in PRP group were subjected to intratendinous injections of $4 \mathrm{~mL}$ PRP with weekly interval (day 0, w1, w2, w3) under the guidance of ultrasonography. Representative tendon specimens from all animals were collected 30, 60, and 90 days post operation (PO) for histopathological examination. The obtained clinical and histopathological results reveled that PRP application improved the healing of SDFT compared to the control group, through increasing and acceleration of angiogenesis, fibrogenesis, collagen deposition and remodeling in the injured tendon matrices.
\end{abstract}

Keywords: Tendon Repair, Platelets Rich Plasma, SDFT Injury, Equine Limb, Growth Factor

\title{
Introduction
}

Equine digital flexor tendons are important weight-bearing structures at rest and during motion and play an important role in equine rapid locomotion. Injuries of the flexor tendons are caused by multiple factors but most commonly by direct trauma or over strain [1]. The superficial digital flexor tendons (SDFT) are more susceptible to injuries than the deep digital flexor tendons (DDFT) due to its superficial anatomic arrangement in the lower limbs, besides that the forelimbs carry about $60 \%$ of the animal weight [1]

The cross-sectional area of the SDFT is smallest in the mid-metacarpal region. Also, the blood supply deficiency at mid- fore cannon region of the SDFT may result in rupture during exercise [2]. Laceration of the digital flexor tendon is usually of traumatic origin and range in the severity from minor unilateral rupture to complete bilateral rupture [3].
Various techniques of digital flexors tenorrhaphy have been described to provide a strong tendon anastomosis including using of prosthetic materials, tendon transplantation, tendon shielding and tissue engineering [4]. Composites made from different biomaterials and cells are reported in other many studies to facilitate repair or to serve as potential replacement tissue. In addition, the exogenous application of cytokines has been done on injured tendons to promote healing $[4,5]$.

Recently, PRP has been used in equine as a natural biological product for wound healing enhancement particularly in ligaments and tendon injuries [6]. Many studies reported that injection of PRP into the injured tendons is the prioritized regenerative therapy to treat tendinopathies [7]. The PRP is the plasma fraction of autologous blood having concentrated platelets above baseline [8]. The most important features of autologous PRP therapy are easy preparation, absence of 
immunological response in the treated organism and any light mechanical stimulation can cause them to release their growth factors [9]. The main components of PRP are growth factors, leukocytes, fibrinogen, vasoactive and chemotactic agents and high concentration of platelets [10]. The regenerative effects of PRP related mainly to the high concentration of reparative growth factors [11]. These factors include platelet-derived growth factor (PDGF), insulin like growth factor (IGF-I), basic fibroblast growth factor (bFGF), vascular endothelial growth factor (VEGF), hepatocyte growth factor (HGF), epidermal growth factor, and stromal cell derived factor $1 \alpha$ [12]. These factors have been shown to enhance tendon regeneration and healing [13, 14]. Therefore, this study was performed to prospectively evaluate the influence of PRP on the restoration of SDFT in donkeys.

\section{Material and Methods}

\section{Animals}

Eighteen clinically apparently healthy male donkeys of different ages (3-6) years old and of different weights $(250-350 \mathrm{~kg})$ purchased from local markets at Zagazig City, Sharkia Governorate, Egypt, were included in this study. The animals were housed and managed in the isolation stables of the Faculty of Veterinary Medicine, Zagazig University and in accordance to the guides provided by the Committee of Animal Welfare and Research Ethics, Faculty of Veterinary Medicine, Zagazig University, Egypt.

For all donkeys, the general physical examination including heart rate, respiration rate and rectal temperature were recorded. Specific examination of the musculoskeletal system was applied using ultrasonography to exclude tendon affections. The animals were classified into two equal groups; group I: (control group) and group II was exposed to PRP injection in the gap between the two cut ends. Each group was further sub divided into three subgroups according to the time of euthanasia at 30, 60 and 90 days.

\section{Anesthesia}

Sedation was induced via intravenous injection of xylazine $\mathrm{HCl}$ (Xyla- Ject@Adwia co, $10^{\text {th }}$ of Ramadan City, Egypt) at a dose of 1 $\mathrm{mg} / \mathrm{kg}$ body weight. Then, the animals were deeply narcotized with chloral hydrate 10\% (Chloral hydrate ${ }^{\circledR}$ PanreacQuimica, Espana) at a dose of $5 \mathrm{gm} / 50 \mathrm{~kg} \mathrm{BW}$ [15].

\section{Surgical Procedure}

Under aseptic condition, $8 \mathrm{~cm}$ midmetacarpus linear skin incision was made over the palmer aspect of the right forelimb. The SDFT was completely transected $(1 \mathrm{~cm})$ from its full thickness. The ends of transected tendon were re-apposed with a single locking loop suture pattern using number 2 nylon suture material (Figure 1a). Subcutaneous tissue and paratenon were closed separately using number I polypropylene suture material (Polypropylene ${ }^{\circledR}$ Euro surgical limited, London) with simple continuous pattern. Skin closure was accomplished using number 2 silk® (International sutures manufacturing co, Egypt). Fiber glass slab was applied in the cranial aspect of the operated limb, with slight flexion of the fetlock joint. Slabs were applied for 8 weeks postoperatively, and were changed regularly after 14 days within this period for the removal of the skin sutures and assessment of the clinical parameters.

\section{PRP preparation}

Twenty $\mathrm{mL}$ anti-coagulated venous blood with Acid Citrate -Dextrose solution ${ }^{\circledR}$ (ACD, Sigma Company. Germany) was centrifuged at $5600 \mathrm{rpm}$ for 10 minutes to separate the platelet poor plasma (PPP) from red blood cells and Buffy coat. The most superior plasma, and the Buffy coat were removed in sterile test tube then centrifuged again at $2400 \mathrm{rpm}$ for another 10 minutes for separation of PPP from PRP and finally calcium chloride ${ }^{\circledR}$ (Elgomhoria co, Egypt) was added to PRP for activation after [16].

\section{Application of PRP}

Four $\mathrm{mL}$ of platelets rich plasma was injected at the day of surgery and for four times/one week interval (day0, w1, w2, w3) under the guidance of ultrasonography (Figure 1b). 


\section{Postoperative care}

Post-operative antibiotic Pen and strept ${ }^{\circledR}$ (Norbrook company. N. Ireland) was injected I.M for five successive days. Antiinflammatory Flunxinmeglumine ${ }^{\circledR}$ (Norbrook company. N. Irland. UK) in a dose of $1.1 \mathrm{mg}$ $/ \mathrm{kg}$ body weight) and anti-tetanic serum ${ }^{\circledR} 1500$ IU (VACSERA, A.R.E) were injected I.M in the day of surgery. After slab removal, a shoe with Calkins was applied on the operated limb for another one month. Hand-walking of the animals applied for 10 minutes daily and after 30 days postoperatively.

\section{Healing evaluation \\ Clinical observation}

The clinical index score was evaluated according to El-Shafaey et al. [17] for the for assessment of clinical parameters in operated donkeys at 30, 60, 90 days post-surgery. Table 1 summarizes the clinical index score.

Table 1: Clinical index score of the animals under investigation

\begin{tabular}{ll}
\hline Clinical index & score \\
\hline Limb circumference & $0-12 \mathrm{~cm} ; 1-13 \mathrm{~cm} ; 2-14 \mathrm{~cm} ; 3-15 \mathrm{~cm}$ \\
Lameness & 0-no lameness: 1- mild; 2- moderate; 3- severe \\
pain & 0-no pain: 1- mild; 2- moderate; 3- severe \\
discomfort & 0-Comfort; $\quad$ 1- discomfort \\
\hline
\end{tabular}

\section{Ultrasonographic evaluation}

This was performed with the ultrasound machine with a linear probe of $7.5 \mathrm{MHz}$ at 30 , 60 and 90 days postoperatively.

\section{Histopathological evaluation}

Donkeys were humanely euthanized using saturated magnesium sulfate administered intravenously at 30, 60 and 90 days postoperatively for samples collection. Representative tendon specimens from all animals were taken and fixed immediately in
$10 \%$ buffered neutral formalin, then a fivemicron thick paraffin sections were prepared, stained by Hematoxylin and Eosin and Masson's trichrome [18] stains and examined microscopically [19].

\section{Results}

\section{Clinical index}

According to the clinical results, limb circumference, lameness, pain and discomfort are scored as showed in Table 2 and Table 3.

Table 2: Clinical index score of control donkeys affected with superficial digital flexor tendon rupture at 30 , 60 and 90 days post operation

\begin{tabular}{llll}
\hline score & & & \\
\hline & $\mathbf{3 0}$ days P.O & $\mathbf{6 0}$ days P.O & $\mathbf{9 0}$ days P.O \\
\cline { 2 - 4 } Limb circumference & 1 & 2 & 3 \\
Lameness & 3 & 3 & 2 \\
pain & 3 & 2 & 1 \\
discomfort & 1 & 1 & 1 \\
\hline
\end{tabular}

Table 3: Clinical index score of donkeys affected with superficial digital flexor tendon rupture injected with PRP at 30, 60 and 90 days post operation

score

\begin{tabular}{llll}
\hline & 30 days P.O & 60 days P.O & 90 days P.O \\
\hline Limb circumference & 1 & 2 & 0 \\
Lameness & 2 & 1 & 0 \\
pain & 2 & 1 & 0 \\
discomfort & 1 & 1 & 0 \\
\hline
\end{tabular}

\section{Ultrasonographic evaluation}

The control group at 30 days post operation, SDFT showed presence of hypo echoic content at the site of segmental defect and acoustic shadowing under the nonabsorbable suture material. At 60 days, disorientation of the fibers represented by 
hyper echoic fibrous tissue and presence of hypo echoic content while at 90 days, SDFT showed well-formed and oriented tendon fiber with sub coetaneous reaction represented by an echoic fluids and fibrous reaction between SDFT and DDFT (Figure 1c). In PRP injected group, the SDFT treated with platelets rich plasma showed segmental defect represented by more fibrous tissue with minimal anechoic content and adhesion between SDFT and
DDFT at 30 days. Sixty days PO, the newly formed tendon fibers were oriented at the site of operation with no inflammatory reaction and no adhesion between SDFT and DDFT, while at 90 days PO, the SDFT showed more oriented newly formed tendon fiber at the site of segmental defect without any inflammatory reaction and no adhesions between SDFT and DDFT (Figure 1d).
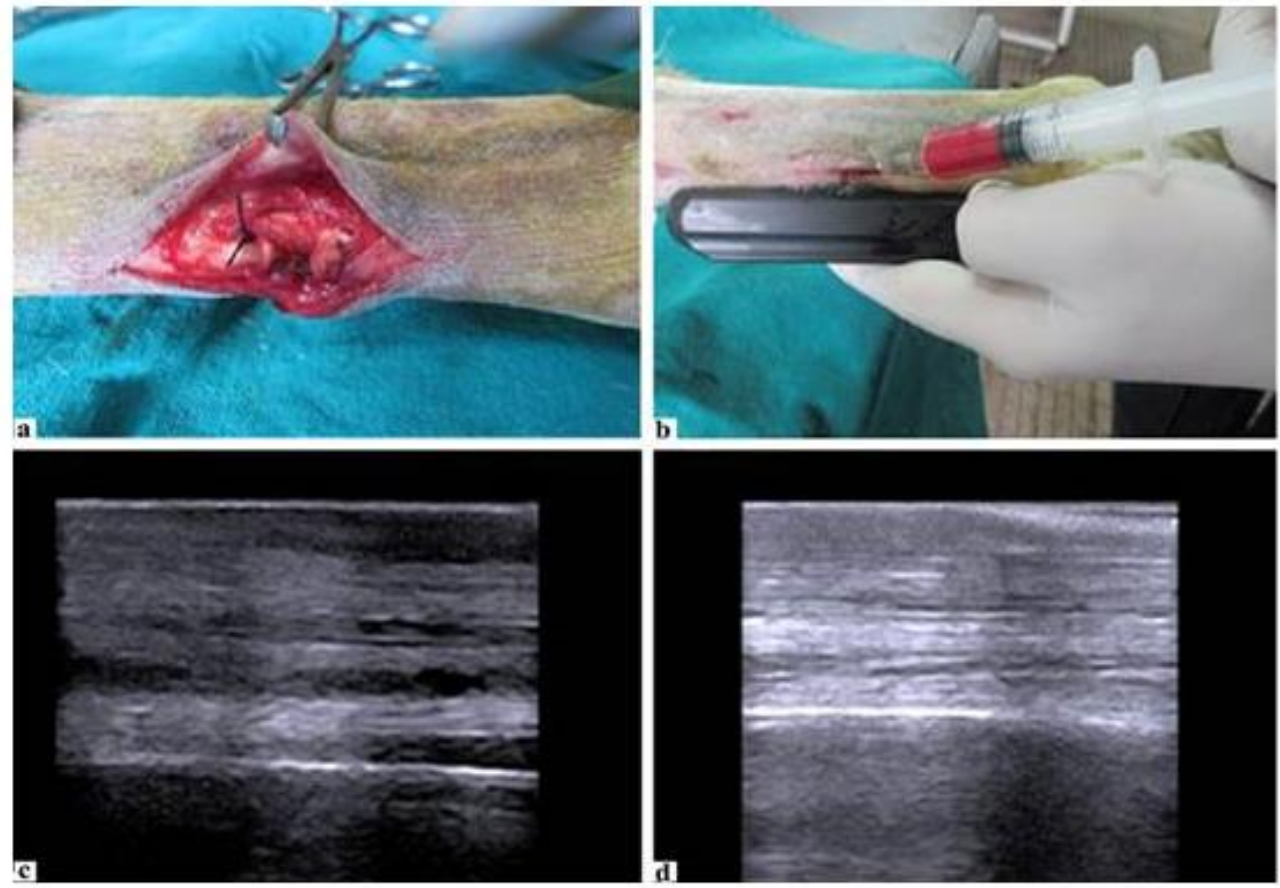

Figure 1: a- The ends of transected tendon were re apposed with a single locking loop suture pattern using number 2 nylon suture material. b -Application of PRP under the guidance of ultrasonography after one week. c- longitudinal sonogram of SDFT (control group), 90 days PO, showing well-formed and oriented tendon fiber with sub cutaneous reaction represented by an echoic fluids and fibrous reaction between SDFT and DDFT. d- Longitudinal sonogram of SDFT of PRP-treated group, 90 days PO, showing more oriented newly formed tendon fiber at the site of segmental defect without any inflammatory reaction and no adhesions between SDFT and DDFT.

\section{Histopathological results}

Thirty days PO, the microscopic examination of tissue specimens obtained from the repaired SDFT of the control group revealed extensive tendinous cellularity, numerous neovascularization with presence of necrotic tissue, focal hemorrhages and numerous polymorphonuclear cell infiltrations (Figure 2.1). In the PRP treated group, the tissue specimens obtained at the same time revealed granulation tissue with neovascularization and numerous active fibroblasts, scanty inflammatory cells and few collagen fibers with absence of necrosis (Figure
2.2). Specimens stained by Masson's Trichrome stain from the control group showed few disorganized collagen fibers with few numbers of blood vessels (Figure 2.3), while in the PRP treated group the collagen fibers were in a moderate density and well organized (Figure 2.4). Sixty days PO, the tendon specimens of the control group revealed moderate tendinous cellularity, marked neovascularization, moderate amounts of misaligned collagen fibers infiltrated with mononuclear inflammatory cells (Figure 2.5), while specimens taken from the tendons of PRP treated group showed moderate amounts of well-organized collagen bundles and few active round fibroblasts (Figure 2.6). 
The specimens stained by Masson's trichrome stain revealed moderate amounts of collagen fibers with numerous blood vessels in the control group (Figure 2.7), while the PRP treated group showed moderate amounts of collagen fibers with less blood vessels (Figure 2.8). Ninety days $P O$, the tendon specimens of the control group showed less tendinous cellularity, abundant amounts of disorganized collagen bundles, numerous blood vessels and few mononuclear inflammatory cells (Figure 2.9), while in the PRP treated group the tendon specimens had almost normal histological picture with well-organized collagen bundles with less cellularity (Figure 2.10). Specimens stained with trichrome stain showed abundant but disorganized collagen fibers in the control group (Figure 2.11), while in PRP treated group showed abundant well-organized collagen fibers (Figure 2.12).

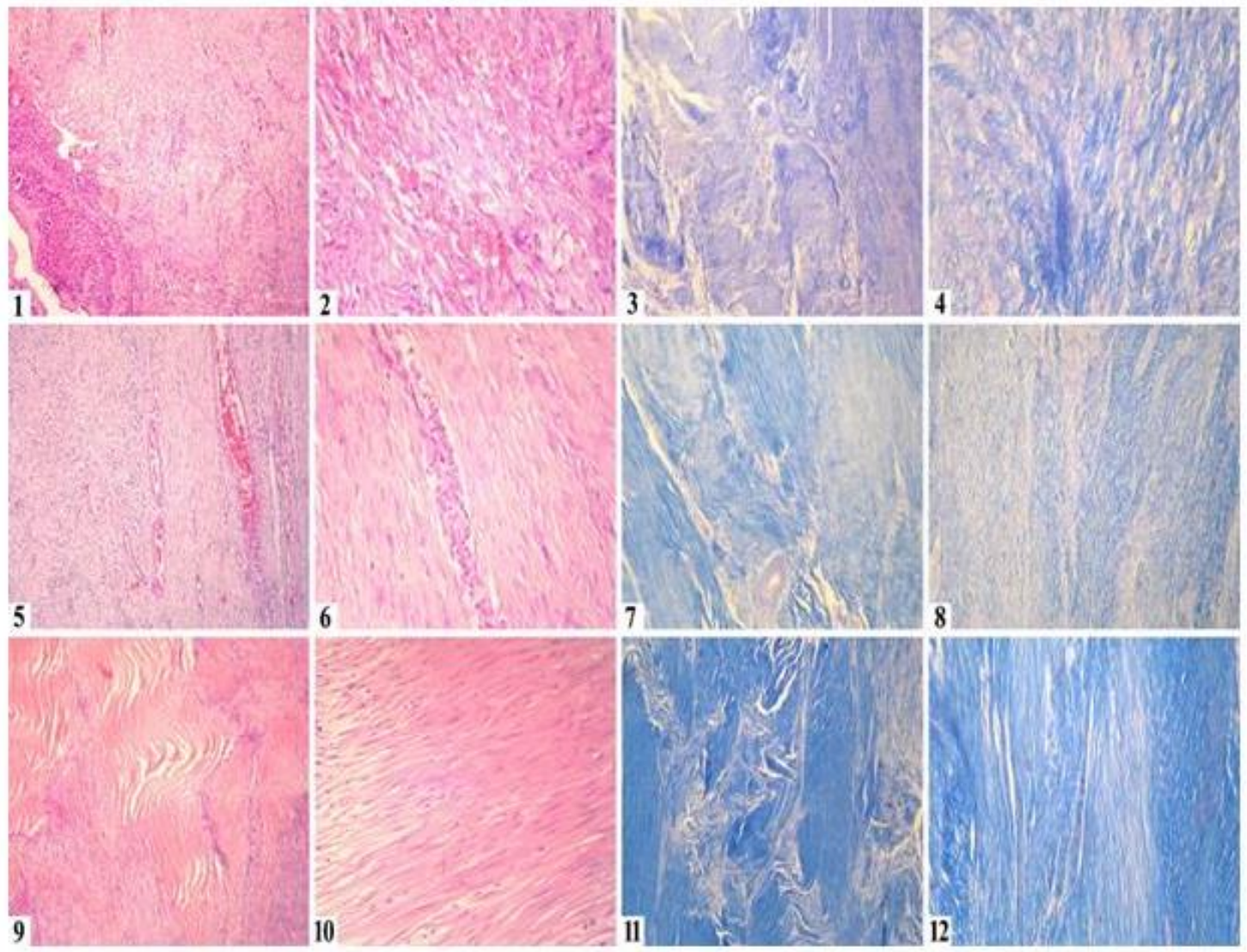

Figure 2: 1. Photomicrograph of SDFT of control group, 30 days PO, showing extensive tendinous cellularity, marked neovascularization, necrotic tissue, focal hemorrhages and numerous polymorphonuclear cell infiltrations, H\&E stain, X100. 2. Photomicrograph of SDFT of PRP-treated group, 30 days PO, showing granulation tissue with neovascularization and numerous active fibroblasts, scanty inflammatory cells and few collagen fibers, H\&E stain, X400. 3. Photomicrograph of SDFT of control group, 30 days PO, showing few disorganized collagen fibers with few numbers of blood vessels, Masson's trichrome stain, X100. 4. Photomicrograph of SDFT of PRP-treated group, 30 days PO, showing collagen fibers with a moderate density and well organization, Masson's trichrome stain, X400. 5. Photomicrograph of SDFT of control group, 60 days PO, moderate tendinous cellularity, marked neovascularization, and moderate amounts of misaligned collagen fibers infiltrated with mononuclear inflammatory cells, H\&E stain, X100.6. Photomicrograph of SDFT of PRP-treated group, 60 days PO, showing moderate amounts of well-organized collagen bundles and few active round fibroblasts, H\&E stain, X400. 7. Photomicrograph of SDFT of control group, 60 days PO, showing moderate amounts of collagen fibers with numerous blood vessels, Masson's trichrome stain, X100. 8. Photomicrograph of SDFT of PRP-treated group, 60 days PO, showing moderate amounts of collagen fibers with less blood vessels, Masson's trichrome stain, X100. 9. Photomicrograph of SDFT of control group, 90 days PO, showing less tendinous cellularity, abundant amounts of disorganized collagen bundles, numerous blood vessels and few mononuclear inflammatory cells, H\&E stain, X400. 10. Photomicrograph of SDFT of PRP-treated group, 90 days PO, showing well-organized collagen bundles with less cellularity, H\&E stain, X400. 11. Photomicrograph of SDFT of control group, 90 days PO, showing abundant disorganized collagen fibers, Masson's trichrome stain, X100. 12. Photomicrograph of SDFT of PRP-treated group, 90 days PO, showing abundant well-organized collagen fibers, Masson's trichrome stain, X100. 


\section{Discussion}

Superficial digital flexor tendon injuries represent the most common cause of lameness in equine, which decrease the economic value of the racing or drafting animal. The high risk of SDFT injury is attributed to its superficial location and the stress induced through it [20]. The present study was designed to evaluate the influence of PRP application in the traumatic injuries of SDFT. The process of healing of tendons is much more difficult than any other tissue in the body due to the healing process particularly the remodeling phase seldom restore the original tendon structure of longitudinal fiber bundles [21,22]. The main goal of PRP treatment is controlling the healing process to stimulate the fibroblast cell division, increase collagen deposition, favorite angiogenesis and improve the remodeling process to restore the tendon structure at its original strength with minimal adhesions and scare formation [23]. The present clinical and histopathological results emphasis that proper application of PRP in SDFT injuries in donkeys was very useful in the healing process.

Clinical observation of the operated donkeys at 30 days PO revealed increase in limb circumference, pain reaction, lameness and discomfort in both groups, while animals of PRP group the animals showed no limb swelling, moderate lameness and pain. This indicated the priority of PRP on tendon healing. The same was demonstrated in the other group at 60 and 90 days with increase of all scores. Moreover, the 90 days PRP group showed normal index score (no swelling, pain, lameness and discomfort) and these results agreed with those of Mostafa et al. [13], who approved that intra tendentious injection of PRP demonstrated improvement of clinical parameters than control group injected with normal saline. In accordance, other studies emphasized also that intra tendentious PRP decrease the inflammatory process, enhance tendon biological function, and morphologically reconstitute the injured tissue by early granulation of defects and minimized scar tissue and adhesions [1, 24]. All these findings were also described in our findings. Therefore, the improvement of scoring and parameter assessment in the present study was attributed to the role of activated intratendinous injection of PRP. Also, Zhang et al. [25] hypothesized that PRP having the hepatocyte growth factor (HGF) which was the reason of anti-inflammatory effects responsible for the pain, heat and swelling rescue effect of the PRP. Moreover, the improvement assessment in the present study is attributed to the role of activated intratendinous injection of PRP as proved ultra-sonographically and histopathologically. However, in the PRP treated group, the ultrasonography at 30 days appeared more echogenic denoting repair of SDFT with minimal anechoic content and adhesion between SDFT and DDFT. Similar findings have been reported during the 90 days in control group, these finding are in parallel with Mostafa et al. [13] who concluded that during this time the lesion showed resolution of inflammatory reaction. At 60 days till the end of study at 90 days, gradual increased echogenicity was observed on the fibers appeared more parallel and more organized without adhesion between SDFT and DDFT. However, during healing, there was deposition of granulation tissue and scar tissues formation. At this stage, tendon sonogram could not be distinguished from normal tendons. This progression revealed good quality tendon repair as described in the present work and supported by other studies [26,27and28]. These results could be attributed to the powerful and long-term analgesic and anti-inflammatory effect of intra tendentious PRP via its growth factors. Also, different authors attributed these findings to paramount regenerative role of intratendinous PRP which enhance early granulation formation, cellular proliferation and differentiation and gradual arrangement of tendon fibers bundle [6, 29]. These findings were supported histopathologically in the present study and in another reported one [30].

Histopathologically, the hallmark effects of PRP injection in the tendons tissues were increased angiogenesis, fibroplasia, and collagen deposition and accelerating the process of remodeling in the PRP treated group compared to the control one. Moreover, the inflammatory phase of wound healing had been shortened with minimal hemorrhages, edema, necrosis, adhesions and scar 
formations in the PRP group. The exact mechanisms of PRP on the inflammatory response after acute tendon injury is not excluded yet, but many studies postulated that the therapeutic effects of PRP in tendon repair could be attributed to the high content of PRP in many growth factors and anti-inflammatory cytokines such as PDGF, IGF-I, bFGF, VEGF and HGF, EGF, DAF, platelet factor 4, ECGF, FGF and stromal cell derived factor $1 \alpha[6,11-$ 13]. These factors had major effects on tendon repair via promoting angiogenesis, fibroblast proliferation, leukocyte chemotaxis, collagen deposition, and remodeling [29-31].

\section{Conclusion}

In the present study, injection of autologous PRP in SDFT in donkeys proved favorable healing of traumatic tendon injury. It motivated cell proliferation and collagen deposition, and accelerated remodeling and angiogenesis in the injured matrix, which promote repair of traumatic tendon injuries and lacerations.

\section{Conflict of interest}

All the authors have no conflict of interest to declare.

\section{References}

[1] O'Sullivan, C. B. (2007): Injuries of the Flexor Tendons: Focus on the Superficial Digital Flexor Tendon. Clin Tech Equine Pract 6(3):189-197.

[2] Patterson-Kane, J .C. and Firth, E. C. (2009): The pathobiology of exerciseinduced superficial digital flexor tendon injury in Thoroughbred racehorses. The Veterinary Journal, 181(2): 79-89.

[3] Thorpe, C. T.; Clegg, P. D. and Birch, H. L. (2010): A review of tendon injury: Why is the equine superficial digital flexor tendon most at risk? Equine Veterinary Journal, 42 (2):174-180.

[4] Hooffman, A. and Gross, G. (2006): Tendon and ligament engineering from cell biology to in vivo application. Regenerative Med: 1(4):563-574.

[5] James, R.; Kesturu, G.; Balian, G. and Chhabra, A. B. (2008): Tendon biology, biomechanics, repair, growth factors, and evolving treatment options. J Hand Surg Am, 33(1):102-12.

[6] Zuffova, K.; Krisova, S. and Zert, Z. (2013): Platelet rich plasma treatment of superficial digital flexor tendon lesions in racing Thoroughbreds. Veterinarni Medicina, 58 (4): 230-239.

[7] Park, G.; Kwon, D. R.; Cho, H. K.; Park, J. and Park, J. H. (2017): Distribution of Platelet-rich Plasma after UltrasoundGuided Injection for Chronic Elbow Tendinopathies. Journal of Sports Science and Medicine, 16(1): 1-5.

[8] Marx, R. E. (2001): Platelet-rich plasma (PRP) what is PRP and what is not PRP? J Implant Dent, 10(4): 225-228.

[9] Kimura, A.; Ogata, H.; Yazawa, M.; Watanabe, N.; Mori, T. and Nakajima, T. (2005): The effects of platelet-rich plasma on cutaneous incisional wound healing in rats. Journal of Dermatological Science, 40(3): 205-208.

[10] Anila, S. and Nandakumar, K. (2006): Applications of Platelet Rich Plasma for Regenerative Therapy in Periodontics. Trends Biomate Artif Organs, 20(1):7883.

[11] Wang, J. H. C. (2006): Mechanobiology of tendon. Journal of Biomechanics, 39(9): 1563-1582.

[12] Sarmiento, J. A. F.; Domı'nguez, J. M.; Granados, M. M.; Morgaz, J.; Navarrete, R.; Carrillo, J. M.; Villamandos, R. J. F.; Mũnoz-Rasc, P.; JuanaMartı́n de las Mulas.; Yolanda Mill'an.; -Balletb, M. G. and Cugat, R: (2013): Histological Study of the Influence of Plasma Rich in Growth Factors (PRGF) on the Healing of Divided Achilles Tendons in Sheep. Journal of Bone and Joint Surgery, 95(3):246-255.

[13] Mostafa, M. B.; Al-Akraa, A. M.; and Khalil, A. H. (2016): Ultrasonographic assessment of superficial flexor tendon (SDFT) core lesion treated with platelets rich plasma (PRP) in donkeys (Equus Asinus). Benha Veterinary Medical J, 29(2): 274-282. 
[14] Singla, A. and Jain, M. (2017): Biological Regeneration of Tissues Latest Therapeutic Approach Using Platelet Rich Plasma. Blood Res Transfuse J, 1(1):1-3.

[15] Hall, L. W.; Clarke, K. W. and Trim, C.M. (2001): Veterinary anesthesia, 10th edition, Saunders, Philadilphia, USA, pp. 225-461.

[16] Marx, R.E, (2004): Platelet-Rich Plasma: Evidence to Support Its Use. J Oral Maxillofac Surg. 62: 489-496.

[17] El-Shafaey, A. A.; Karrouf, G. I. A. And Zaghloul A. (2012): A Comparative Study Evaluating Three Bioscaffold Augmentation Devices Used for Superficial Digital Flexor Tenorrhaphy in Donkeys (Equus Asinus) by Magnetic Resonance Imaging and Ultrasonography. Journal of Equine Veterinary Science, 32(11):728-739.

[18] Bancroft, J.D. and Stevens, A. (1996): Theory and practice of Histological techniques. 4th ed. Chorchill, Livingston, Edinburg, London, Melbourne and New York. PP 96-104.

[19] Suvarna, S.K.; Layton, C. and Bancroft, J.D. (2013): Bancroft's Theory and Practice of Histological Techniques, 7th Edition, Churchill Livingstone Elsevier, Oxford.

[20] Smith, R.K.W. (2008): Tendon and ligament injury. In Proceedings of the 54th Annual Convention of the American Association of Equine Practitioners; San Diego, California, pp. 475-501.

[21] Marx, R. E.; Carlson, E. R.; Eichstaedt, R.M.; Schimmele, S. R.; Strauss, J. E. and Georgeff, K. R. (1998): Platelet Rich Plasma:-Growth Factors Enhancement for Bone Grafts. Oral Surg Oral Med Oral Pathol Oral Radiol Endod, 85(6):638-646.

[22] Ferraro, G.; Meierhenery, b.; Glide, k. and Osburn, D (2011): Platelets- rich plasma; improving treatment for ligament and tendon injuries. The Horse Report, 29(1):1-11.
[23] Yuan, T., Zhang C.Q and Wang J. H.C. (2013): Augmenting tendon and ligament repair with platelet-rich plasma (PRP). Muscles Ligaments Tendons J, 3(3): 139-149.

[24] Fortier, L. A. and Smith, R. K. W. (2008): Regenerative medicine for tendinous and ligamentous injuries of sport horses. Vet Clin North Am Equine Pract, 24(1): 191-201.

[25] Zhang, J.; Middleton, K.; Fu, F. H.; Im, H. J. and Wang J. (2013): HGF Mediates the Anti-inflammatory Effects of PRP on Injured Tendons. PLoS One, 8(6): e67303.

[26] Nicoll. R.G.; Wood, A.K. and Rothwell, T.L. (1992): Ultrasonographical and pathological studies of equine SDFT; initial observations, including tissue characterization by analysis of image grey scale, in a Thoroughbred gelding. Equine Vet J, 24(4):318-320.

[27] Crass, J.; Genovese, R.; Render, J. and Bellon, E. M. (1992): MRI, ultrasound and histopathologic correlation of acute and healing equine tendon injuries. Vet Radiol Ultrasound, 33(4):206-216.

[28] Marr, C.; McMillan, I.; Boyd, J.; Wright, N. and Murray, M. (1993): Ultrasonographic and histopathological findings in equine superficial digital flexor tendon injury. Equine vet $\mathrm{J}$, 25(1):23- 29.

[29] Bosch, G.; Moleman, M.; Barneveld, A.; van Weeren, P. R.; van Schie, H. T. M. (2011): The effect of platelet-rich plasma on the neovascularization of surgically created equine superficial digital flexor tendon lesions. Scandinavian Journal of Medicine and Science in Sports, 21(4): 554-561.

[30] Aljobory K. H. (2009): An experimental study of the effect of autologous platelet rich plasma on the healing process of tendon in donkeys A. Iraqi Journal of Veterinary Sciences, 23(Suppl I):81-85. 
[31] Wiltfang, J.; Schlegel, K. A.; SchultzeMosgau, S.; Nkenke, E.; Zimmermann, R. and Kessler, P. (2003): Sinus floor augmentation with beta tri calcium phosphate (beta-TCP): does platelet-rich plasma promote its osseous integration and degradation? Clin Oral Implants Res, 14(2): 213-218.

\section{الملخص العربى}

تأثير البلازما الغنية بالصفائح الدموية على ألتئام تمزق الوترالأصبعي السطحي القابض فى الحمير ( دراسة تجريبية )

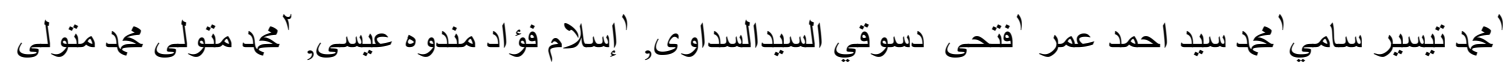

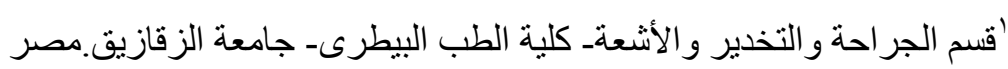

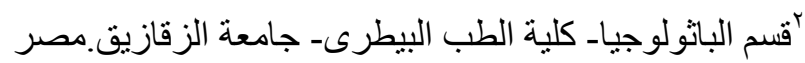

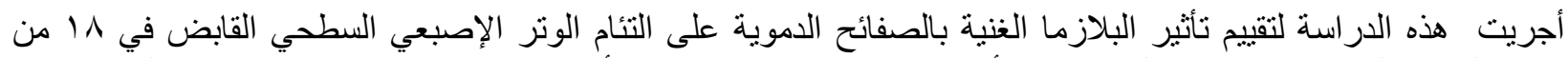

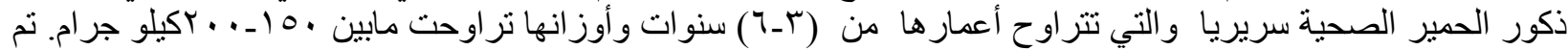

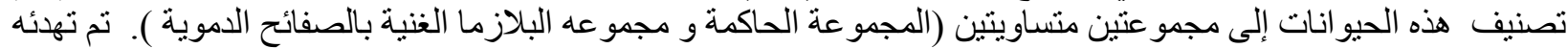

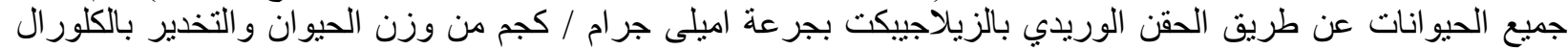

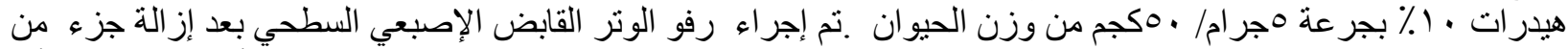

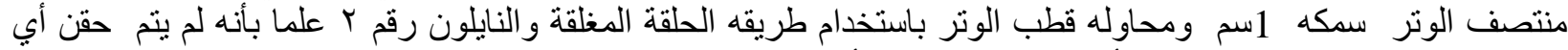

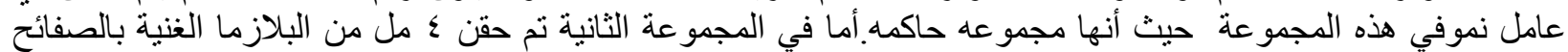

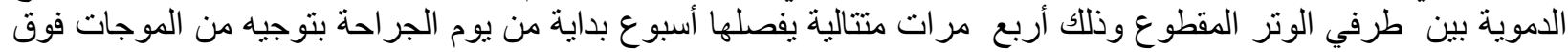

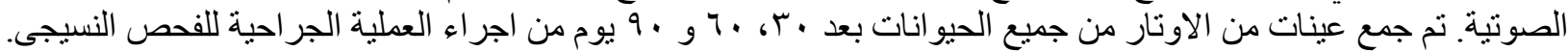

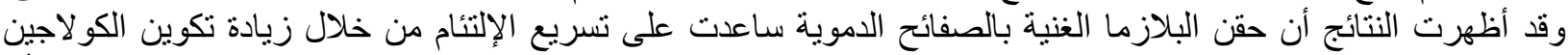

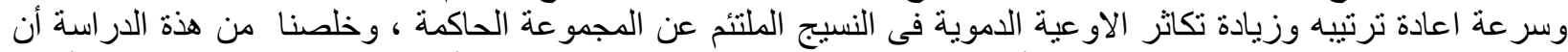
حقن البلازما الغنية بالصفائح الدموية داخل أتسجة الوتر التهائة المصاب يؤدي إلى إعادة تكاثر الأوعية الدموية وتسريع التئام الأوتار المصابة مقارنة بالمجمو عة الحاكمة. 